\title{
Special Issue on Rock Fracturing and Fault Activation: Experiments and Models
}

\author{
Selected Papers Presented at the 13th EURO-Conference on Rock Physics and \\ Geomechanics-The Guéguen Conference Held on 2-6 September 2019 in Potsdam, Germany
}

\author{
Hannes Hofmann ${ }^{1}$. Guido Blöcher ${ }^{1} \cdot$ Arno Zang $^{1,2}$
}

Published online: 27 September 2021

(c) The Author(s) 2021

\section{Introduction}

Since 1998, the EURO-Conference series on Rock Physics and Geomechanics is regularly held at different locations throughout Europe and beyond and is self-organized by the European Rock Mechanics community (Table 1). The conference intends to bring together rock mechanics experts from academia and industry with special emphasis on support for early career scientists. Each conference is dedicated to a topic of particular relevance to the community at the time and frequently results in special issues on these topics (Table 2). The augmentation 'The Guéguen Conference' was added on the occasion of the 70th birthday of Yves Guéguen, one of the main initiators and supporters of the EURO-Conference series.

The '13th EURO-Conference on Rock Physics and Geomechanics-The Guéguen Conference' was held on 2-6 September 2019 in Potsdam, Germany. The overarching theme of the conference was 'Rock fracturing and fault activation: experiments and models'. Given the increasing

This special issue is dedicated to our dear colleague and friend Prof. Ove Stephansson, who was not only one of Sweden's most influential geologists, but also an enthusiastic supporter of the 13th EURO-Conference on Rock Physics and Geomechanics. Ove was actively involved in research, teaching, conferences and publications until he passed away on 19 February 2020. Lilljequist and Zang (2020) look back on his outstanding academic career with personal remarks in a dedicated remembrance article.

Hannes Hofmann

hannes.hofmann@gfz-potsdam.de

1 Helmholtz Centre Potsdam GFZ German Research Centre for Geosciences, Telegrafenberg, 14473 Potsdam, Germany

2 University of Potsdam, Am Neuen Palais 10, 14469 Potsdam, Germany relevance of fracture and fault development and associated induced and triggered seismicity in human subsurface operations such as conventional and unconventional hydrocarbon production, hydrothermal and petrothermal energy utilization, wastewater disposal, energy storage, and rad waste storage, this subject deserves and will attract special attention in the near future. The conference provided a unique opportunity for international researchers and industry experts to discuss latest results and developments on the topic of rock fracturing and fault activation, which is fundamental to safely and economically utilize the subsurface.

This special issue intends to summarize the highlights of the conference programme consisting of 8 keynote lectures, 47 oral presentations and 26 poster presentations given by rock mechanics experts and early career scientists (Fig. 1). The programme was divided into the following eight oral presentation sessions: 'Fluid-driven fractures and seismicity', 'Compaction and damage of porous rock I+ II', 'Laboratory fracture and rock characterization studies', 'Poroelasticity and seismicity of reservoir rocks', 'Simulation of fractures and faults', 'Hydraulic, thermal and mechanical cyclic loading at multiple scales' and 'Hydraulic fracturing, hydromechanics and fracture permeability'. Abstracts of all conference contributions can be found in Hofmann and Spalek (2019).

This special issue consists of 19 scientific papers which are based on these conference contributions and all of which address different important aspects relevant to the variety of industrial applications outlined above. We want to highlight that rock fracturing and fault activation are two very different processes and that both hard data measured in experiments as well as analytical and numerical models together yield a powerful path to solve industrial and societal challenges associated with the utilization of the subsurface based on scientific evidence. 
Table 1 Summary of past EURO-conferences

\begin{tabular}{|c|c|c|c|}
\hline Year & Location & Organizer & Topic \\
\hline 1998 & Aussois, France & Y. Guéguen, M. Boutéca & Pore pressure, scale effect, and the deformation of rocks \\
\hline 1999 & Edinburgh, UK & G. Couples, I. Main & The relationship between damage and localization \\
\hline 2000 & Bad Honnef, Germany & H.J. Kümpel, C. Clauser & Thermo-hydro-mechanical coupling in fractured rock \\
\hline 2003 & Kijkduin, The Netherlands & A. Makurat & Micromechanics, flow and chemical reactions \\
\hline 2004 & Potsdam, Germany & G. Dresen, S. Shapiro, O. Stephansson, A. Zang & Scaling laws in space and time \\
\hline 2005 & Oléron, France & C. David, M. Le Ravalec & $\begin{array}{l}\text { Rock physics and geomechanics in the study of reser- } \\
\text { voirs and repositories }\end{array}$ \\
\hline 2007 & Erice, Italy & S. Vinciguerra, Y. Bernabé & $\begin{array}{l}\text { Natural hazards: thermo-hydro-mechanical processes } \\
\text { in rocks }\end{array}$ \\
\hline 2009 & Ascona, Switzerland & L. Burlini, P. Baud, A. Schubnel & $\begin{array}{l}\text { Thermo-hydro-chemo-mechanical coupling in rock } \\
\text { physics and mechanics }\end{array}$ \\
\hline 2011 & Trondheim, Norway & R. Holt, S. Johnsen & Linking laboratory, computational and field evidence \\
\hline 2014 & Aussois, France & C. Viggiani, P. Besuelle, F. Renard & Multi-scale rock mechanics and rock physics \\
\hline 2015 & Ambleside, UK & P. Benson, P. Rowley, P. Meredith & $\begin{array}{l}\text { Holistic rock physics: integrating theory, observation } \\
\text { and application }\end{array}$ \\
\hline 2017 & Ma’ale HaHamisha, Israel & E. Shalev, R. Weinberger, V. Lyakhovksy, Y. Hatzor & Bridging between rock physics and structural geology \\
\hline 2019 & Potsdam, Germany & $\begin{array}{l}\text { H. Hofmann, G. Zimmermann, G. Blöcher, H. } \\
\text { Milsch, A. Spalek, A. Zang, O. Stephansson, K.Y. } \\
\text { Kim }\end{array}$ & $\begin{array}{l}\text { Rock fracturing and fault activation: experiments and } \\
\text { models }\end{array}$ \\
\hline
\end{tabular}

Table 2 Summary of special issues on past EURO-Conferences

\begin{tabular}{|c|c|c|c|}
\hline Year & Journal & Topic & Reference \\
\hline 1999 & $\begin{array}{l}\text { Oil \& Gas Science and Technology - Rev. } \\
\text { IFP }\end{array}$ & $\begin{array}{l}\text { Pore pressure, scale effect and the deforma- } \\
\text { tion of rocks }\end{array}$ & $\begin{array}{l}\text { Boutéca and Guéguen (1999) } \\
\text { https://doi.org/10.2516/ogst:1999055 }\end{array}$ \\
\hline 2003 & Pure and Applied Geophysics & $\begin{array}{l}\text { Thermo-hydro-mechanical coupling in } \\
\text { fractured rock }\end{array}$ & $\begin{array}{l}\text { Kümpel (2003) } \\
\text { https://doi.org/10.1007/978-3-0348-8083-1 }\end{array}$ \\
\hline 2005 & $\begin{array}{l}\text { International Journal of Rock Mechanics \& } \\
\text { Mining Sciences }\end{array}$ & Rock physics and geomechanics & $\begin{array}{l}\text { Makurat and Zimmerman (2005) } \\
\text { https://doi.org/10.1016/j.ijrmms.2005.05.001 }\end{array}$ \\
\hline 2006 & Pure and Applied Geophysics & Rock damage and fluid transport, Part I & $\begin{array}{l}\text { Dresen et al. (2006) } \\
\text { https://doi.org/10.1007/3-7643-7712-7 }\end{array}$ \\
\hline 2006 & Pure and Applied Geophysics & Rock damage and fluid transport, Part II & $\begin{array}{l}\text { Zang et al. (2006) } \\
\text { https://doi.org/10.1007/s00024-006-0114-2 }\end{array}$ \\
\hline 2007 & $\begin{array}{l}\text { Geological Society of London, Special } \\
\text { Publications }\end{array}$ & $\begin{array}{l}\text { Rock physics and geomechanics in the study } \\
\text { of reservoirs and repositories }\end{array}$ & $\begin{array}{l}\text { David and Le Ravalec-Dupin (2007) } \\
\text { https://doi.org/10.1144/SP284.1 }\end{array}$ \\
\hline 2007 & $\begin{array}{l}\text { Geological Society of London, Special } \\
\text { Publications }\end{array}$ & $\begin{array}{l}\text { The relationships between damage and } \\
\text { localization }\end{array}$ & $\begin{array}{l}\text { Couples and Lewis (2007) } \\
\text { https://doi.org/10.1144/SP289.1 }\end{array}$ \\
\hline 2009 & Pure and Applied Geophysics & Rock physics and natural hazards & $\begin{array}{l}\text { Vinciguerra and Bernabé (2009) } \\
\text { https://doi.org/10.1007/978-3-0346-0122-1 }\end{array}$ \\
\hline 2011 & Tectonophysics & $\begin{array}{l}\text { Thermo-hydro-chemo-mechanical couplings } \\
\text { in rock physics and rock mechanics }\end{array}$ & $\begin{array}{l}\text { Baud and Schubnel (2011) } \\
\text { https://doi.org/10.1016/j.tecto.2010.11.002 }\end{array}$ \\
\hline 2021 & Rock Mechanics and Rock Engineering & $\begin{array}{l}\text { Rock fracturing and fault activation: experi- } \\
\text { ments and models }\end{array}$ & This issue \\
\hline
\end{tabular}

We admit, however, that fracture mechanical principles and rock physics elements behind rock fracturing and fault activation may be similar, and that the joint discussion of fracturing and faulting, therefore, has a long tradition in the rock mechanics and rock engineering community.

\section{Rock Fracturing}

\subsection{Laboratory Experiments}

Forbes Inskip et al. (2021) measured tensile strength and fracture toughness of Nash Point limestone, a typical 


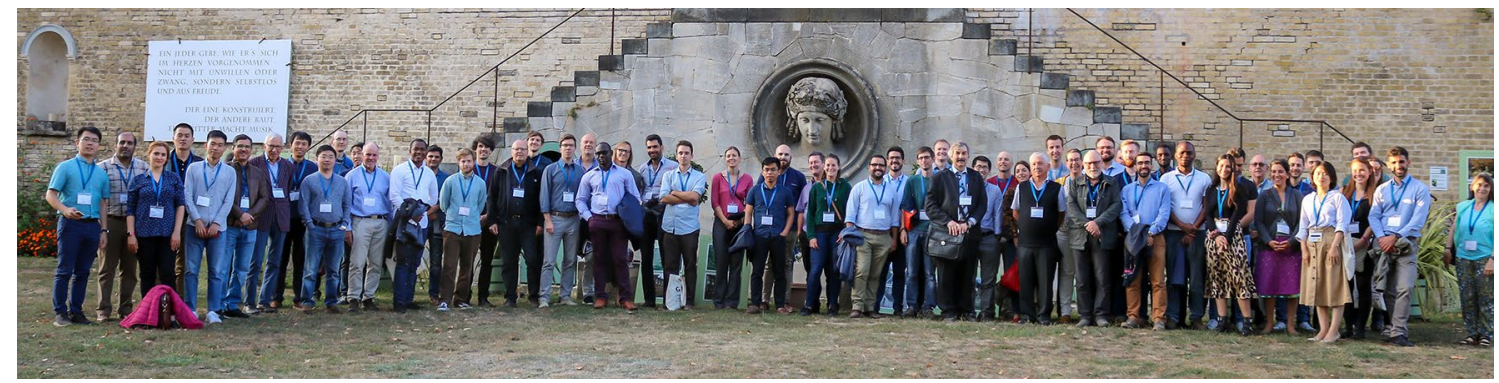

Fig. 1 Participants of the '13th EURO-Conference on Rock Physics and Geomechanics-The Guéguen Conference' during the social event at the Winzerberg Potsdam

hydrocarbon reservoir rock, in three principal fracture orientations and found it to be roughly isotropic in terms of microstructure and fracture properties. Additionally, they discuss how layered sequences (i.e., limestone and shale layers) may influence vertical fracture crossing.

Meng et al. (2021) quantified the effect of bedding anisotropy and crack closure on the effective stress behaviour of clayey sandstones. Their data show that bedding anisotropy has a significant influence on the effective stress coefficient for permeability, but little effect on the effective stress coefficient for pore volume change.

Geremia et al. (2021) performed water flooding experiments of dry, critically loaded Obourg Chalk samples in a conventional triaxial test apparatus which resulted in a significant reduction in mechanical strength. They observed a brittle-ductile transition between low- to high-confining pressures and propose that the failure might be controlled by a mechanical coupling between water-invaded zone and dry zone.

Jung et al. (2021) analysed in laboratory hydraulic fracturing experiments the fatigue behaviour of cylindrical granite samples subject to different continuous and cyclic injection schemes. They found that the number of cycles to failure increases exponentially with decreasing maximum pressure and that cyclic injection led to more acoustic emissions, lower seismic energy and higher Gutenberg-Richter b values as compared to the continuous injection cases.

Kluge et al. (2021) initiated a shear zone in Flechtingen Sandstone and Odenwald Granite laboratory samples under in situ conditions using a punch-through shear test setup. They found that permeability did not significantly change in the sandstone samples while it increased by two orders of magnitude for the granite samples and that further shear displacement resulted in a further, but small permeability increase. They associated the difference in permeability evolution in the two rock types to a difference in the width of the shear zones.

Martin-Clave et al. (2021) performed cyclic mechanical (axial) loading tests on five rock samples with different types and amounts of secondary minerals under a confining pressure of $25 \mathrm{MPa}$ to improve the understanding on safe cyclic underground gas storage in salt caverns. They observed a strength weakening effect by high secondary mineral content (e.g., anhydrite layers) through larger brittle deformation and a change elastic moduli and porosity.

Fazio et al. (2021) investigated the effect of matrix permeability on hydraulic fracturing by performing injection experiments in highly permeable Bentheim Sandstone, in low-permeability Crab Orchard Sandstone, and sleeve fracturing experiments. They found that no fracture developed in the permeable Bentheim Sandstone, a hydraulic fracture propagates fast and continuously in the low permeability Crab Orchard Sandstone and a fracture is induced gradually and episodic in the sleeve fracturing experiment in Bentheim Sandstone. They attribute this behaviour to leak-off, which is dictated by the rock matrix permeability.

\subsection{Modelling Studies}

Yang et al. (2021) derived and applied an evaluation procedure for mode I fracture toughness determination from numerical models and three-point bending tests at confining pressures up to $30 \mathrm{MPa}$ with different sealing methods. While the determined toughness generally increased significantly with confining pressure up to some tens of MPa, they found that the apparent toughness determined for jacketed specimens was larger than that of varnished ones. They explain their observations by micro-crack closure and suggest that non-linearity effects may not be as severe at depths beyond a few kilometres as previously thought.

Zhao et al. (2021) developed a flexible wall approach to improve the simulation of triaxial compression tests in discrete element models. They constructed their models based on CT images and validated them against triaxial compression test data. The models were then used to investigate the effect of inclusions in coal samples on strength, deformation, and damage. They found that a higher proportion of high strength inclusions increases the peak strength of a coal sample. 
Jacquey et al. (2021a) review concepts of the thermomechanics theory and extend it by a thermodynamically consistent modelling approach that includes rate-dependent critical state-line models for porous rocks. They use their model to analyse strain localization behaviour.

Jacquey et al. (2021b) extend this theory to account for poromechanics and dissipative inelastic processes. Based on experimental data they demonstrate how their model accounts for the macroscopic response of triaxial loading experiments with focus on the transition from dilation to compression and the resulting range of localization styles from shear dilation to compactions bands.

Spetz et al. (2021) propose a modified phase-field model for simulating the evolution of mixed mode (tensile and shear) fractures in porous artificial rocks. The simulated results are compared to experimental data and to other current phase-field methods, both qualitatively and quantitatively. It is shown that the proposed model is able to capture the commonly observed propagation pattern of wing cracks followed by secondary cracks driven by compressive stresses. Additionally, the typical types of complex crack patterns observed in experimental tests are successfully reproduced.

\section{Fault Activation}

\subsection{Laboratory Experiments}

Ji et al. (2021) investigated the fluid injection-induced slip of a critically stressed natural fracture in a granite core sample subject to different pressure-controlled and volumecontrolled monotonic and cyclic water injection schemes. While they found that cyclic injection with restricted pressure could reach similar displacements with lower slip rates as compared to monotonic injection, they also observed fast unstable slip after a certain displacement was reached.

Cheng and Milsch (2021) performed an experimental study on fracture closure of aligned and displaced tensile fractures as well as saw-cut fractures of soft Flechtingen Sandstone and hard Fontainebleau sandstone under confining pressures between 5 and $30 \mathrm{MPa}$. They found that depending on fracture surface roughness, fracture displacement can significantly enhance fracture aperture, and that rough fractures, strong asperities, and a certain fracture offset are required for fractures under stress to stay open to fluid flow.

\subsection{Modelling Studies}

Su et al. (2021) performed two-dimensional discrete element modelling of dynamic fault rupturing using Particle Flow Code 2D (PFC2D) to understand the related spatio-temporal stress re-orientations measured by a borehole strain meter in the direct vicinity of the Ganzi-Yushu fault in the eastern Tibetan Plateau before and after the 2010 Ms 7.3 Yushu earthquake sequence. They highlight the influence of structural complexity and off-fault damage by co-seismic fault slip on the local stress field.

Lyakhovsky and Shalev (2021) performed a poro-elastic damage rheology modelling study on stable versus runaway fracture growth. They separate diffusion-controlled rupture growth, considered to be stable, from runaway fracture where the rupture propagates beyond the pore pressure front. They found that the amount of permeability increase with damage and the injection pressure are two major factors governing the stability of the modelled faults and fault branching.

Parastatidis et al. (2021) demonstrate that localized effective medium (LEM) models are an accurate and efficient method to retrieve fracture properties from inverse modelling of seismic waves in comparison to less effective explicitly modelled zero-thickness frictional slip surfaces or less accurate effective medium models. They note that the thickness of the localized effective medium layer representing the fracture becomes important when the frequency is high, and the normal stiffness is low.

Shapiro and Dinske (2021) investigated high-stressdrop earthquakes induced by underground fluid injection or production. They derived a relationship between seismogenic index and stress drop showing that the seismogenic index increases with average stress drop of induced seismic events. Additionally, they formulated a simple phenomenological model of stress drop of induced earthquakes that shows how a decrease of fault cohesion during the earthquake rupture process and larger effective stresses could lead to high-stress-drop earthquakes.

Deng et al. (2021) introduced a new methodology to determine fracture diffusivity from numerical simulations. This was done by fitting the numerically computed spatiotemporal pressure field with the solution of an equivalent parallel plate model. They used their model to investigate hydraulic diffusivity reduction caused by fracture closure and surface roughness.

Acknowledgements We would like to thank the other members of the local organizing committee Günter Zimmermann, Harald Milsch, Angela Spalek, and Ove Stephansson, the scientific advisory committee Eyal Shalev, Philip Meredith, Robert Zimmerman, Patrick Baud, Georg Dresen, Christian David, Rune Martin Holt, Gioacchino Viggiani, and Sergio Vinciguerra, the sponsors and supporters Korea Institute of Construction Technology (KICT), German Research Foundation DFG and Helmholtz Centre Potsdam GFZ German Research Centre for Geosciences, all conference participants and authors, and the tremendous support of all reviewers and the Rock Mechanics and Rock Engineering managing editor Mariacristina Bonini and Editor-in-Chief Jean Sulem.

Funding Open Access funding enabled and organized by Projekt DEAL. 
Open Access This article is licensed under a Creative Commons Attribution 4.0 International License, which permits use, sharing, adaptation, distribution and reproduction in any medium or format, as long as you give appropriate credit to the original author(s) and the source, provide a link to the Creative Commons licence, and indicate if changes were made. The images or other third party material in this article are included in the article's Creative Commons licence, unless indicated otherwise in a credit line to the material. If material is not included in the article's Creative Commons licence and your intended use is not permitted by statutory regulation or exceeds the permitted use, you will need to obtain permission directly from the copyright holder. To view a copy of this licence, visit http://creativecommons.org/licenses/by/4.0/.

\section{References}

Baud P, Schubnel A (2011) Preface. Tectonophysics 503(1-2):1-2. https://doi.org/10.1016/j.tecto.2010.11.002

Boutéca M, Guéguen Y (1999) Editorial. Dossier: Euroconference on pore pressure, scale effect and the deformation of rocks, 16-20 Nov. 1998, Aussois, France. Oil Gas Sci Technol Rev 54(6):663666. https://doi.org/10.2516/ogst:1999055

Cheng C, Milsch H (2021) Hydromechanical Investigations on the Selfpropping Potential of Fractures in Tight Sandstones. Rock Mech Rock Eng. https://doi.org/10.1007/s00603-021-02500-4

Couples GD, Lewis H (2007) Introduction: the relationship between damage and localization. Geol Soc London, Spec Pub 289:1-6. https://doi.org/10.1144/SP289.1

David C, Le Ravalec-Dupin M (2007) Rock physics and geomechanics in the study of reservoirs and repositories. Geol Soc London Spe Pub 284:1-14. https://doi.org/10.1144/SP284.1

Deng Q, Blöcher G, Cacace M, Schmittbuhl J (2021) Hydraulic diffusivity of a partially open rough fracture. Rock Mech Rock Eng. https://doi.org/10.1007/s00603-021-02629-2

Dresen G, Stephansson O, Zang A (2006) Rock damage and fluid transport, Part I. In: Dresen G, Zang A, Stephansson O (eds) Rock damage and fluid transport, Part I Pageoph Topical Volumes. Birkhäuser, Basel. https://doi.org/10.1007/3-7643-7712-7_1

Fazio M, Ibemesi P, Benson P, González-Bedoya D, Sauter M (2021) The role of rock matrix permeability in controlling hydraulic fracturing in sandstones. Rock Mech Rock Eng. https://doi.org/10. 1007/s00603-021-02580-2

Forbes Inskip ND, Meredith PG (2021) Fracture properties of Nash point limestone and implications for fracturing of layered carbonate sequences. Rock Mech Rock Eng. https://doi.org/10.1007/ s00603-021-02403-4

Geremia D, David C, Descamps F, Mendérez B, Barnes C, Vandycke S, Dautriat J, Esteban L, Sarout J (2021) Water-induced damage in microporous carbonate rock by low-pressure injection test. Rock Mech Rock Eng. https://doi.org/10.1007/s00603-021-02411-4

Hofmann H, Spalek A (2019) Rock fracturing and fault activation: Experiments and models, 13th EURO-conference on rock physics and geomechanics - the Guéguen conference (Potsdam 2019), Potsdam: GFZ German research centre for geosciences. https:// doi.org/10.2312/GFZ.4.8.2019.017

Jacquey AB, Regenauer-Lieb K (2021a) Thermomechanics for geological, civil engineering and geodynamic applications: Rate-dependent critical state line models. Rock Mech Rock Eng. https://doi. org/10.1007/s00603-021-02397-z

Jacquey AB, Regenauer-Lieb K, Cacace M (2021b) Thermomechanics for geological, civil engineering and geodynamic applications: numerical implementation and application to Bentheim sandstone. Rock Mech Rock Eng. https://doi.org/10.1007/ s00603-021-02582-0
Ji Y, Zhuang L, Wu W, Hofmann H, Zang A, Zimmermann G (2021) Cyclic water injection potentially mitigates seismic risks by promoting slow and stable slip of a natural fracture in granite. Rock Mech Rock Eng. https://doi.org/10.1007/s00603-021-02438-7

Jung SG, Diaz MB, Kim KY, Hofmann H, Zimmermann G (2021) Fatigue behavior of granite subjected to cyclic hydraulic fracturing and observations on pressure for fracture growth. Rock Mech Rock Eng. https://doi.org/10.1007/s00603-021-02383-5

Kluge C, Blöcher G, Barnhoorn A, Schmittbuhl J, Bruhn D (2021) Permeability evolution during shear zone initiation in lowporosity rocks. Rock Mech Rock Eng. https://doi.org/10.1007/ s00603-020-02356-0

Kümpel HJ (2003) Special issue 'Thermo-hydro-mechanical coupling in fractured rock. In: Kümpel HJ (eds) Thermo-hydro-mechanical coupling in fractured rock. Pageoph topical volumes. Birkhäuser, Basel. https://doi.org/10.1007/978-3-0348-8083-1_1

Lilljequist R, Zang A (2020) Ove Stephansson, 1938-2020. GFF. https://doi.org/10.1080/11035897.2020.1809823

Lyakhovsky V, Shalev E (2021) Runaway versus stable fracturing during hydraulic stimulation: insights from the damage rheology modeling. Rock Mech Rock Eng. https://doi.org/10.1007/ s00603-021-02395-1

Makurat A, Zimmerman RW (2005) Preface. Int J Rock Mech Min Sci 42(7-8):871-872. https://doi.org/10.1016/j.ijrmms.2005.05.001

Martin-Clave C, Ougier-Simonin A, Vandeginste V (2021) Impact of second phase content on rock salt rheological behavior under cyclic mechanical conditions. Rock Mech Rock Eng. https://doi. org/10.1007/s00603-021-02449-4

Meng F, Li X, Baud P, Wong T-F (2021) Bedding anisotropy and effective stress law for the permeability and deformation of clayey sandstones. Rock Mech Rock Eng. https://doi.org/10.1007/ s00603-020-02306-w

Parastatidis E, Hildyard MW, Nowacki A (2021) Simplified seismic modelling of fractured rock - how effective is the localised effective medium compared to explicit representation of individual fractures. Rock Mech Rock Eng. https://doi.org/10.1007/ s00603-021-02601-0

Shapiro SA, Dinske C (2021) Stress drop, seismogenic index and fault cohesion of fluid-induced earthquakes. Rock Mech Rock Eng. https://doi.org/10.1007/s00603-021-02420-3

Spetz A, Denzer R, Tudisco E, Dahlblom O (2021) A modified phasefield fracture model for simulation of mixed mode brittle fractures and compressive cracks in porous rock. Rock Mech Rock Eng. https://doi.org/10.1007/s00603-021-02627-4

Su Z, Yoon JS, Zang A, Tang L, Gu H, Zhu C (2021) Stress reorientation by earthquakes near the Ganzi-Yushu strike-slip fault and interpretation with discrete element modelling. Rock Mech Rock Eng. https://doi.org/10.1007/s00603-021-02443-w

Vinciguerra S, Bernabé Y (2009) Introduction. In: Vinciguerra S, Bernabé Y (eds) Rock physics and natural hazards. Pageoph topical volumes. Birkhäuser, Basel. https://doi.org/10.1007/ 978-3-0346-0122-1_1

Yang H, Krause M, Renner J (2021) Determination of fracture toughness of mode I fractures from three-point bending tests at elevated confining pressures. Rock Mech Rock Eng. https://doi.org/10. 1007/s00603-021-02432-z

Zang A, Stephansson O, Dresen G (2006) Rock damage and fluid transport, Part II. Pure Appl Geophys 163:2049-2050. https://doi.org/ 10.1007/s00024-006-0114-2

Zhao Y, Konietzky H, Herbst M (2021) Damage evolution of coal with inclusions under triaxial compression. Rock Mech Rock Eng. https://doi.org/10.1007/s00603-021-02436-9

Publisher's Note Springer Nature remains neutral with regard to jurisdictional claims in published maps and institutional affiliations. 